\title{
Proximity to four bikeway types and neighborhood-level cycling mode share of male and female commuters
}

\section{Kay Teschke}

\author{
University of British Columbia \\ kay.teschke@ubc.ca
}

\author{
Michael Brauer \\ University of British Columbia \\ michael.brauer@ubc.ca
}

\author{
Anna Chinn \\ University of Colorado \\ anna.chinn@colorado.edu
}

\begin{abstract}
We studied 2011 cycling mode share at the census-tract level in Montréal and Vancouver, Canadian cities with relatively high mode shares and diverse bike infrastructure. We examined whether mode share variability, for all commuters and male and female commuters separately, was related to proximity to any bikeway, proximity to four bikeway types, slopes on routes to bikeways, or commute times. Cycling mode shares at the census-tract level varied from 0 to $20.4 \%$. About a third of cycle commuters were female, but this proportion approached parity with males in census tracts with mode shares of $7 \%$ and higher. A one-kilometer closer proximity to any bikeway was associated with four times higher cycling mode share. Proximity to cycle tracks was associated with higher cycling mode shares in both cities. Other bikeway types did not have similar associations in the two cities, and the pattern of results suggested that the networks formed may have been more important than specific bikeway characteristics. Uphill slopes to bikeways were associated with somewhat lower mode shares in bivariate analyses but not in adjusted models. Cycle commuting was most common in neighborhoods with intermediate average commute durations: 20 to 29 minutes. Our results suggest that cycle tracks and bikeways that form a connected network are associated with higher neighborhood cycling commute mode shares. These features appeared even more important to women, and their cycling (or not) was strongly related to overall cycling mode shares.
\end{abstract}

\section{Article history:}

Received: October 5, 2016

Received in revised form:

January 17, 2017

Accepted: May 10, 2017

Available online: June 29, 2017

\section{$1 \quad$ Introduction}

Transport cycling has been repeatedly shown to be associated with increased life expectancy in studies that weigh its benefits (i.e., lower incidence and/or mortality from heart disease, stroke, diabetes, dementia, depression, certain cancers) against its traffic injury risks (Mueller et al., 2015; Oja et al., 2011;

Copyright 2017 Kay Teschke, Anna Chinn \& Michael Brauer

http://dx.doi.org/10.5198/jtlu.2017.943

ISSN: 1938-7849 | Licensed under the Creative Commons Attribution - Noncommercial License 3.0

The Journal of Transport and Land Use is the official journal of the World Society for Transport and Land Use (WSTLUR) and is published and sponsored by the University of Minnesota Center for Transportation Studies. 
Woodcock, Givoni, \& Morgan, 2013). Despite its value, in North America, transport cycling remains uncommon. Country-wide data indicate that the proportion of commute trips by bicycle (commute mode share) is about 1\% in Canada and the United States (Buehler \& Pucher, 2012a).

In countries with little cycling, surveys indicate that route safety concerns are the major deterrent and that designated infrastructure for cycling is the major motivator (Aldred, Elliott, Woodcock, \& Goodman, 2016; Buehler \& Dill, 2016; Winters \& Teschke, 2010). Opinion research is supported by evidence of differences between cities in North America: in those with more bike infrastructure, commute mode shares are considerably higher (Winters, Teschke, Brauer, \& Fuller, 2016; Schoner \& Levinson, 2014; Buehler \& Pucher, 2012b; Dill \& Carr, 2003). Large cities with more bike infrastructure have city-wide mode shares of 2-6\%, while those with little often have mode shares near zero (Winters et al., 2016; Buehler \& Pucher, 2012b). Within cities, there can be even greater differences in cycling mode shares, for example, a reported range of 0 to 34\% across census tracts in a study of 24 US and Canadian cities (Winters et al., 2016). In that study, the first in North America to examine the association between neighborhood-level cycling mode shares and nearby bike infrastructure, a positive association was found.

There is consistent evidence that bike infrastructure in general is associated with more cycling, but could the type of infrastructure also make a difference? Survey data indicate preferences for certain bikeway types (off-street bike paths, cycle tracks, residential street bikeways), especially among those who are most concerned about safety: women and people with children (Aldred et al., 2016; Buehler \& Dill, 2016; Winters \& Teschke, 2010; Dill \& Gliebe, 2008). These stated preferences are supported by studies that show people are willing to increase travel time and distance to use preferred route types (Larsen \& El-Geneidy, 2011; Broach, Dill, \& Gliebe, 2012; Wardman, Tight, \& Page, 2007). To date, the relationship between specific types of bike infrastructure and transport cycling levels has been little studied.

Here we examine factors that influence commuter cycling mode share at the neighborhood (census tract) level. Are mode shares higher when bikeways are closer to where people live and if so, does the type of bikeway make a difference? We examined two of the largest Canadian cities, both with higher than average cycling mode shares and substantial between-neighborhood variability in cycling: Montréal and Vancouver. Both provide cycle tracks, painted bike lanes, residential street bikeways, and off-street bike paths, but the extent of each and the resulting network patterns differ. We examined associations with cycling mode share for different types of bikeway, and whether associations were affected by neighborhood commute duration or slope on the routes to bikeways. Because cycling is much more common among men than women in low cycling countries (Buehler \& Pucher, 2012a) and because women express a stronger hierarchy of route preference (Aldred et al., 2016; Winters \& Teschke, 2010), we also examined whether associations differed for male and female commuters.

\section{$2 \quad$ Methods}

This study used 2011 administrative data on commuting to work and spatial data on distances and slopes along shortest routes from residential parcels to bikeways. The geographic boundaries of the study were defined as the Montréal and Vancouver census consolidated subdivisions. Respectively, these included the island of Montréal (i.e., Baie-d'Urfé, Beaconsfield, Côte Saint-Luc, Dollard-des-Ormeaux, Dorval, Hampstead, Kirkland, Montréal, Montréal-Est, Montréal West, Mount Royal, Pointe-Claire, Sainte-Anne-de-Bellevue, Senneville, and Westmount) and the City of Vancouver and the Musqueam Indian Reserve No. 2, but not the University of British Columbia on the west side of the Vancouver peninsula.

All data were abstracted at the census tract level (Statistics Canada, 2011a), 517 in Montréal and 117 in Vancouver. Fourteen Montréal census tracts were not included because they were uninhabited 
$(\mathrm{n}=6)$, or because data quality or small reporting samples meant data were not released $(\mathrm{n}=8)$. Census tracts approximate neighborhoods and in 2011 in the two study census subdivisions, they had a mean population of 3900 (interquartile range: 2600 to 5000).

\subsection{Commute data}

Commuting data were abstracted from the public release dataset of the National Household Survey (NHS) conducted from May 5 to August 24, 2011 (Statistics Canada, 2011b). The sampling frame was $30 \%$ of households randomly selected from the 2011 Census of Population dwelling list. The Montréal and Vancouver census subdivisions had weighted response rates of $82 \%$ and $78 \%$, respectively (Statistics Canada, 2011c). Commuting questions were restricted to the population aged 15 years and over in private households who worked at some time since January 1, 2010 and who indicated that they either had no fixed workplace address or specified a usual workplace address. The employed population is further age restricted, as indicated by the 2011 Canadian Labor Force Survey: in Montreal and Vancouver, it was dominated by those aged 25 to $54(-70 \%)$, with $14 \%$ aged 15 to $24,13 \%$ aged 55 to 64 , and $3 \%$ aged 65 and over (Statistics Canada, 2011d). NHS commuting questions referred to the job held during the week of May 1-7, 2011. However, if the person did not work that week, the questions were asked about the job held longest since January 1, 2010.

For each census tract, data were abstracted on the total number of commuters and the number of commuters usually using each of the following modes to commute from home to work: cycling; walking; public transit; and car, truck or van as driver or passenger. For each census tract, the proportion of commuters who reported usually using each mode (commute mode share) was calculated. For each census tract, the median time it usually took commuters to get from home to work by any mode was calculated. Commute data were also abstracted and tabulated for females and males separately.

\subsection{Route to bikeway data}

Table 1 details the spatial data layers used to calculate distances from homes to bikeways and slopes of the routes. ESRI Shapefiles were used to perform Geographic Information Systems (GIS) analyses and all GIS analysis was done using ArcGIS 10.2 (Esri Canada, Toronto, ON). Montréal and Vancouver data were projected using the NAD83 Zone UTM $18 \mathrm{~N}$ and $10 \mathrm{~N}$ coordinate systems, respectively. In Montréal, the address point layer was flattened such that only one address point existed per parcel. In Vancouver, property parcel polygon centroids were created by calculating polygon centroid geometry and generating XY point events. Parcels within exclusively industrially or commercially zoned areas were removed from the dataset, leaving only those at which people would be expected to live.

Table 1: Spatial data, format, and sources

\begin{tabular}{lll}
\hline Data & Format & Source \\
\hline Canadian census tracts & Polygons & Statistics Canada \\
Canadian digital elevation model $(25 \mathrm{~m}$ resolution) & Raster surface & GeoGratis Canada \\
Montréal street network & Polylines & Portail données ouvertes Montréal \\
Montréal bikeways & Polylines & Vélo Québec \\
Montréal property addresses & Points & Portail données ouvertes Montréal \\
2012 Montréal land use (utilisation du sol) & Polygons & Données Géoréférencées du Commu- \\
Vancouver streets package & Polylines & nauté métropolitaine de Montréal \\
Vancouver bikeways & Polylines & City of Vancouver Open Data catalogue \\
Vancouver property parcels & Polygons & City of Vancouver Open Data catalogue \\
Vancouver zoning districts & Polygons & City of Vancouver Open Data catalogue \\
\hline
\end{tabular}


Vélo Québec provided a bikeway polyline network for the Island of Montréal that was created in late 2010 and was up to date during the time of the 2011 NHS (personal communication, Mark Jolicoeur, Research Director, Vélo Québec Association, February 23, 2016). Vancouver bikeway polyline data were acquired February 3, 2016, and represented infrastructure as it stood on that day. The Vancouver bikeway network was modified to match the 2011 City of Vancouver Cycle Route Map and Info Guide published in the first quarter of that year (personal communication, Dale Bracewell, Manager, Active Transportation, City of Vancouver, February 23, 2016) to reflect the bikeways present when the 2011 NHS was administered. Vertices along bikeways were densified at 50-meter intervals to represent points of access at roadway intersections and periodically along bikeway polylines to allow for representation of the immediate access of those living along a bikeway. Separate layers were generated for all bikeways and four bikeway types: cycle tracks (alongside streets and also called separated, segregated, or protected bike lanes), on-street painted bike lanes, residential street bikeways (also called bike boulevards), and paved off-street bike paths. Photos showing examples of these bikeway types are provided in Figure 1. These bikeway types were selected because they have been shown in previous research to be preferred and/or safer for cycling, though not equally so (Winters \& Teschke, 2010; Dill \& Gliebe, 2008; Larsen \& El-Geneidy, 2011; Reynolds, Harris, Teschke, Cripton, \& Winters, 2009; Teschke et al., 2012; Lusk et al., 2011). Historical Google Streetview imagery was used to manually check that the classification of bikeway types was the same in the two cities. On-street routes were checked for physically separated versus painted lanes; off-street routes were checked to ensure they were paved bike paths not unpaved trails.
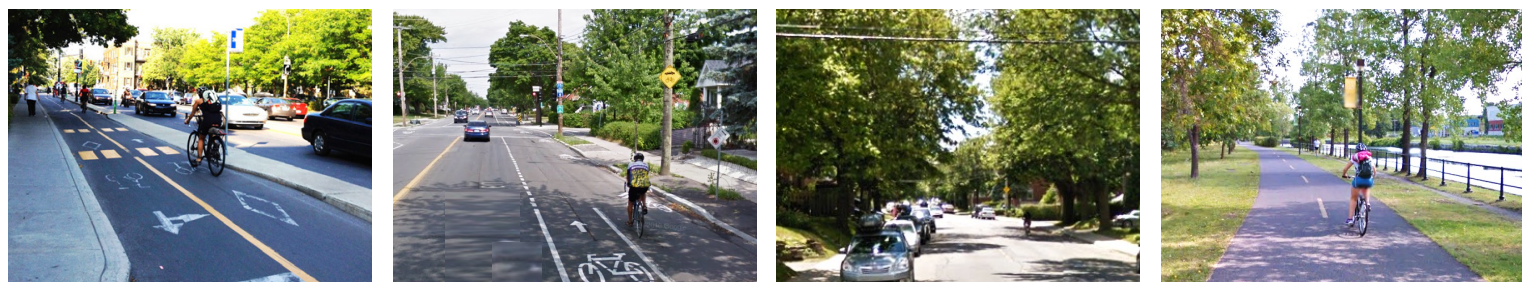

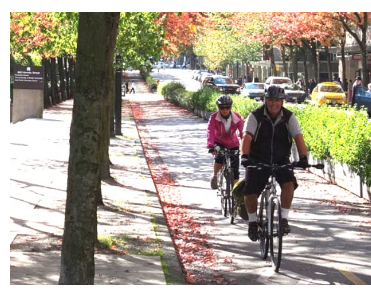

Cycle tracks

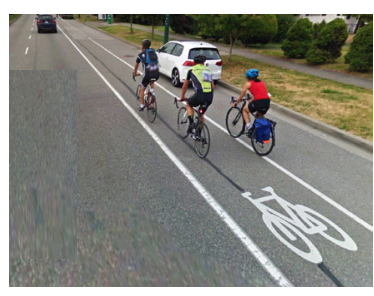

Painted bike lanes

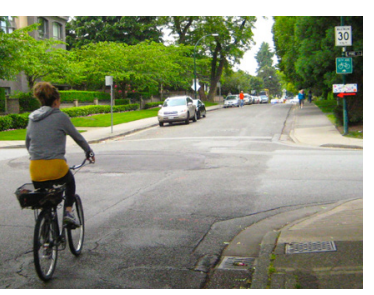

Residential street bikeways

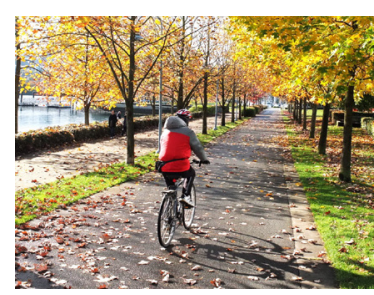

Off-street bike paths

Figure 1: Examples of the four bikeway types examined, top row in Montréal, bottom row in Vancouver (photo credits: authors, Ken Ohrn, Google Streetview)

The street network datasets for each city were built using the total surface displacement along a street to incorporate the elevation component of travel distance. The surface displacement distance from each parcel along the route network to the nearest bikeway access point was calculated for each bikeway type, as well as for the bikeway network as a whole. For each route from a parcel to a bikeway access point, the maximum absolute slope (uphill or downhill) and maximum directional slope (meant to preferentially capture uphill slopes = positive) were calculated using the underlying DEM raster surface by comparing measures of slope at $200 \mathrm{~m}$ intervals along the route. The surface displacement distance to nearest bikeway and slope variables were joined to the associated starting parcel or address and to the appropriate census tract polygons. The GIS variables were summarized as mean values for each census tract. 


\subsection{Data analyses}

All data analyses were conducted using $\mathrm{R}$ (The R Project for Statistical Computing, https://www.rproject.org, accessed February 26, 2016) or JMP 12 (SAS Institute, Cary NC).

Commute and route to bikeway variables were linked via census tract, the unit of analysis. Descriptive statistics (mean, median, SD, maximum, minimum, interquartile range) were calculated for each variable, to summarize the data. Histograms of the distributions of each variable and scatterplots of bivariate relationships between each independent variable and cycling mode share were examined to make decisions about variable transformation or categorization. Correlations between independent variables were also examined to determine if any had correlations above 0.7 that would make inclusion in the same model difficult to interpret (none did).

Inferential analyses examined the associations between cycling commute mode share and each of the following independent variables: proximities to any bikeway and to each of the four individual bikeway types (continuous), maximum directional and absolute slopes to the nearest bikeway (continuous), and commute time ( 4 categories). Initial analyses examined the associations between the dependent variable and each independent variable separately (bivariate/unadjusted analyses). Six models were also developed. The first examined the associations between cycling mode share and proximity to any bikeway, directional slope to the nearest bikeway, and commute time. The second examined the associations between cycling mode share and proximities to each of the four bikeway types, directional slope to the nearest bikeway, and commute time. The third to sixth models repeated the above two analyses for male and female commuters separately; they used male and female commute data (number of commuters, number of cycling commuters, commute times). City was included as an independent variable in every model to account for within-city correlation not explained by the other fixed effects. Because of the different patterns of bikeways in the two cities, interaction terms for city and each bikeway type, commute time, and slope were examined and included where statistically significant. In all cases where the interaction term was not significant, p-values were $>0.25$. The corrected Akaike information criterion (AICc) was used to compare the less and more complex models (e.g., first and second, respectively) in each pair of analyses.

Modelling was done using the generalized linear model with Poisson distribution and log link, and variance estimates were corrected for overdispersion (quasi-Poisson). To model cycling mode share, the dependent variable was the number of cycling commuters and the exposure offset was the number of commuters. Exponentiated coefficients represent the relative rate (i.e., the ratio of cycling commute mode shares) for each unit or category change in the independent variable.

\section{Results}

Table 2 outlines characteristics of the Montréal and Vancouver census consolidated subdivisions at the time of the 2011 Census and National Household Survey. Figure 2 shows maps of the cities, the included census tracts, and their cycling commute mode shares. The Montréal census consolidated subdivision included about one-half of the metropolitan population in census tracts with a broad range of surface areas, reflecting different population densities_from dense urban neighborhoods to more rural areas with densities less than 400 people per square kilometer $(\mathrm{km})$. In contrast, the Vancouver census consolidated subdivision included about one-quarter of the metropolitan population and the census tracts were less variable in size, reflecting more consistently urban neighborhoods. Montréal has colder winters and warmer summers than Vancouver. Vancouver has more rainy days than Montréal (Environment Canada, 2016). 


\subsection{Commuting}

In 2011, the Montréal census consolidated subdivision had an overall cycling commute mode share of $2.7 \%$, with a broad range across census tracts, from 0 to $20.4 \%$ (Table 2, Figure 2). The Vancouver census consolidated subdivision had an overall cycling commute mode share of $4.3 \%$, and a range across census tracts from 0 to $14.9 \%$. The proportion of cycling commuters who were female was similar in the two cities, slightly below and above one-third, though this too varied a great deal by census tract, from 0 to $80 \%$ (both cities).

Table 2: Characteristics of Montréal and Vancouver census consolidated subdivisions in 2011: population, commuters, climate normals

\begin{tabular}{lcc}
\hline & Montréal & Vancouver \\
\hline Population of the census consolidated subdivisions & $1,886,481$ & 605,071 \\
\% of the metro region population & 48.5 & 25.5 \\
Area $\left(\mathrm{km}^{2}\right)$ & 499.5 & 119.4 \\
Population density $\left(\right.$ per $\left.\mathrm{km}^{2}\right)$ & 3,777 & 5,068 \\
\hline Commuter population & 828,290 & 295,365 \\
\% of commuters who were female & 48.4 & 48.9 \\
\% of commuters who usually cycled to work (commute mode share) & 2.7 & 4.3 \\
\% of cycling commuters who were female & 32.2 & 37.5 \\
\hline Annual days with snowfall & 59 & 9 \\
Annual days with rainfall & 104 & 159 \\
Annual days with maximum $>20^{\circ} \mathrm{C}$ & 117 & 77 \\
\hline
\end{tabular}

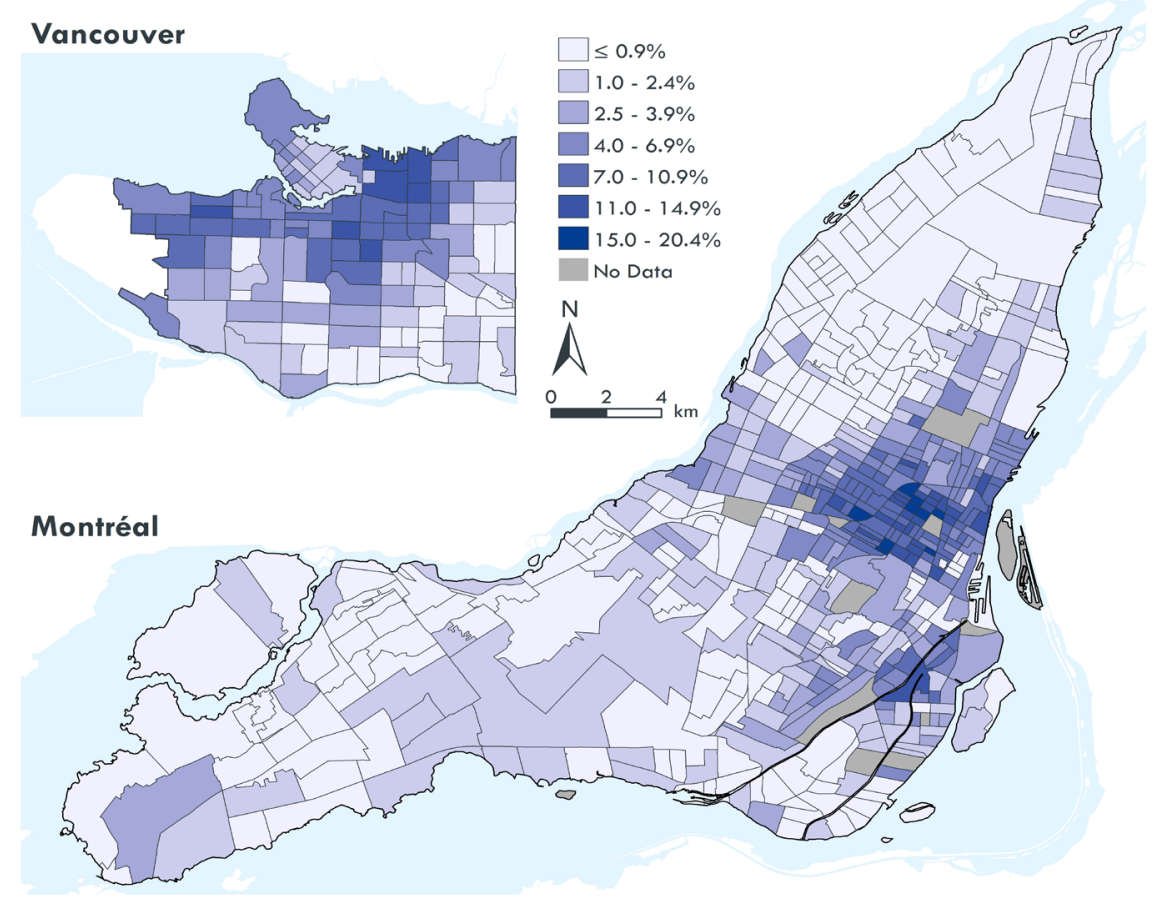

Figure 2: Maps of the Montréal and Vancouver census consolidated subdivisions showing cycling commute mode shares (\%) in 2011 by census tract; scales same for both maps 
Median commute times of census tracts ranged from 12 to 35 minutes and agglomerated at intervals of 5 minutes in four logical groupings, so this variable was categorized. Cycling mode shares of census tracts varied in a non-linear way with commute times (Figure 3). Cycling mode shares were lower in census tracts where commute times were less than 20 minutes and walking was common, and in those where commute times were more than 30 minutes and transit and driving dominated. Cycling had the lowest mode share in every commute time category.

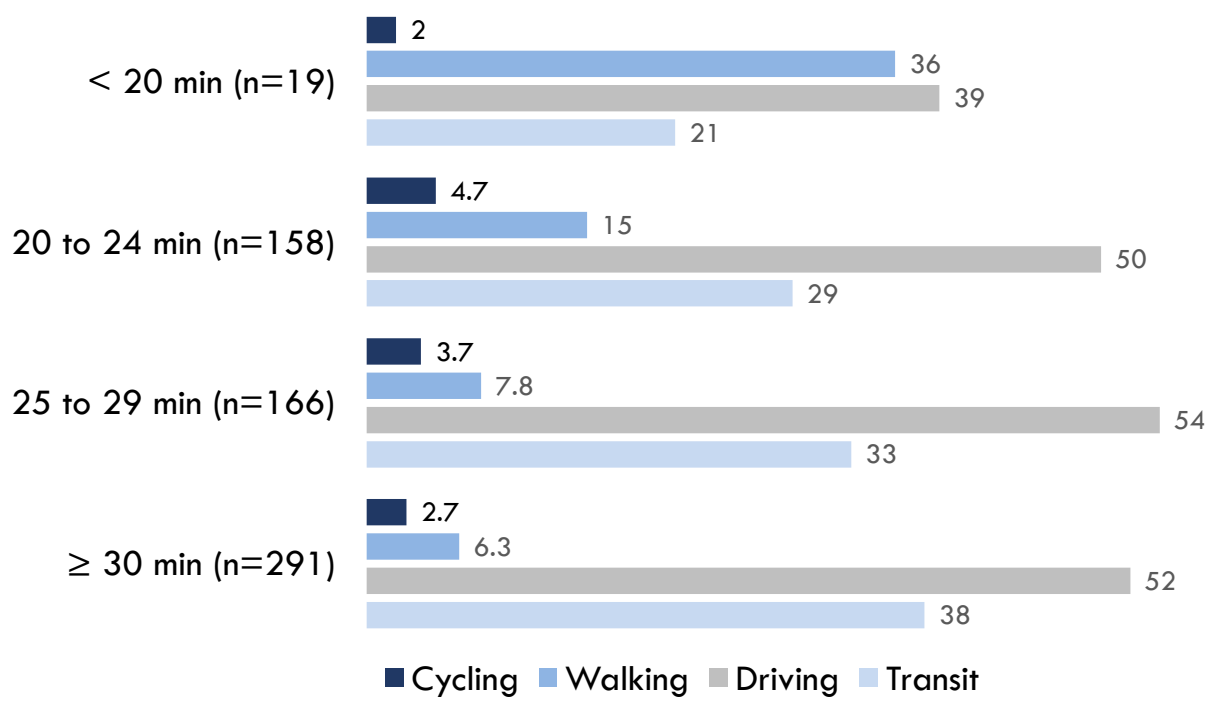

Figure 3: Mean cycling, walking, driving, and public transit commute mode shares (\%) according to median commute time categories of 634 census tracts ( $\mathrm{n}=$ number of census tracts)

\subsection{Routes to bikeways}

Table 3 indicates the lengths of the four bikeway types available in each city in 2011. Figure 4 maps them and shows their $400 \mathrm{~m}$ catchment areas. This distance has been identified in other studies of these cities as a proximity to homes that motivates cycling and as the mean distance cyclists detour to access a bikeway (Larsen \& El-Geneidy, 2011; Winters, Teschke, Grant, Setton, \& Brauer, 2010). The bikeway distributions differed in the two cities. Montréal bikeways provided less overall coverage, especially in the more suburban/rural areas, and the lengths of each bikeway type were similar. Vancouver had a network of residential street bikeways distributed throughout the city. The lengths of other bikeway types were much shorter.

Table 3: Lengths of bikeways in the Montréal and Vancouver census consolidated subdivisions in 2011

\begin{tabular}{lcc}
\hline & Montréal & Vancouver \\
\hline Total kilometers of bikeways & 448 & 241 \\
\hline Kilometers of cycle tracks (separated bike lanes) & 113 & 15 \\
Kilometers of painted bike lanes & 107 & 40 \\
Kilometers of residential street bikeways & 96 & 157 \\
Kilometers of off-street bike paths & 132 & 29 \\
\hline
\end{tabular}




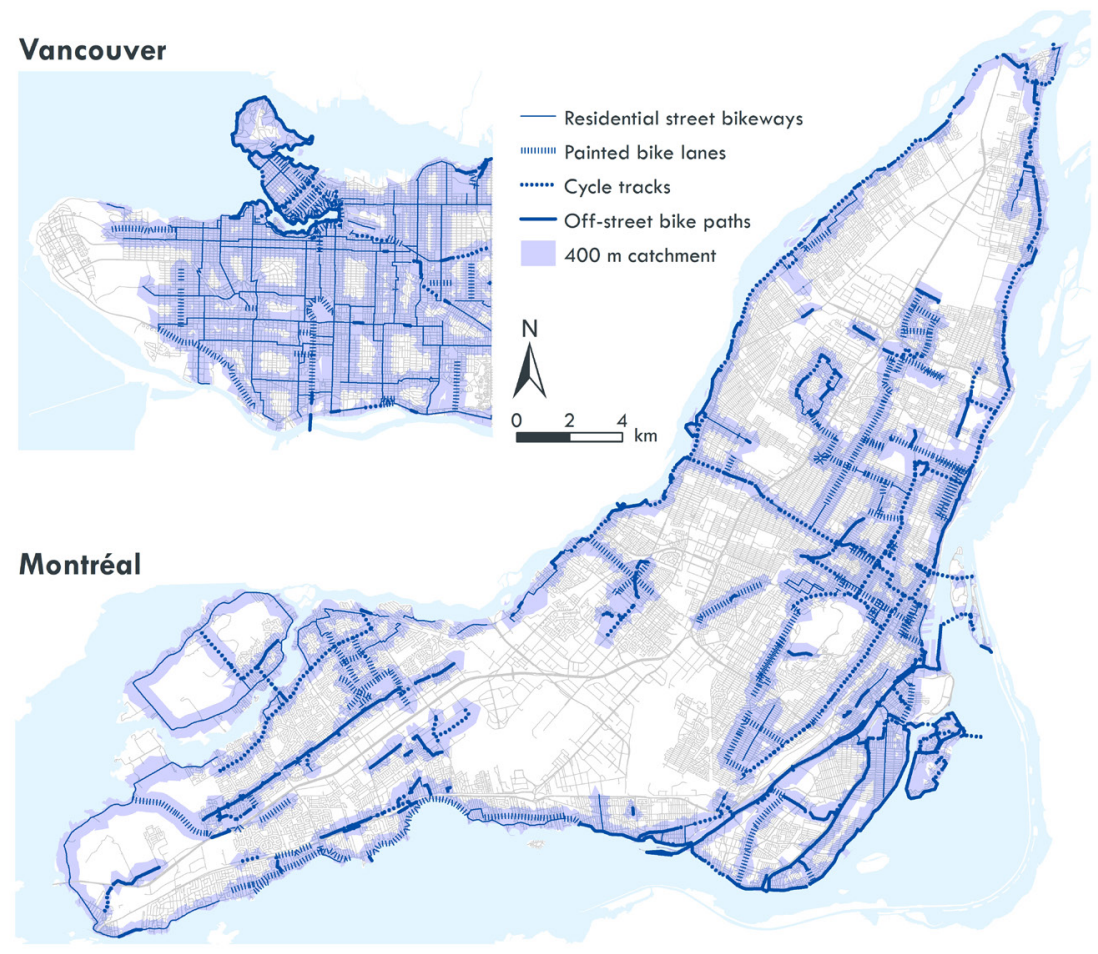

Figure 4: Maps of the Montréal and Vancouver census consolidated subdivisions showing four different bikeway types available in 2011 and a 400-m catchment area around each

Figure 5 shows the distributions of the mean distances within census tracts from residential parcels to any bikeway and to each bikeway type for the two cities separately. In Montréal, the median distance (among census tracts) to the nearest bikeway was $0.37 \mathrm{~km}$, and median distances to each of the four bikeway types were similar: cycle tracks $0.83 \mathrm{~km}$, painted bike lanes $1.0 \mathrm{~km}$, residential street bikeways $0.99 \mathrm{~km}$, and off-street bike paths $0.99 \mathrm{~km}$. In Vancouver, the median distance (among census tracts) to the nearest bikeway was $0.20 \mathrm{~km}$, primarily driven by proximity to residential street bikeways (median $0.24 \mathrm{~km}$ ). Median distances to other bikeway types were longer: cycle tracks $1.6 \mathrm{~km}$, painted bike lanes $0.87 \mathrm{~km}$, and off-street bike paths $1.3 \mathrm{~km}$.

The maximum slopes along the routes from residential parcels to any bikeway were summarized for each census tract. Among census tracts, maximum absolute slopes had a median of $1.1 \%$ and a range of 0 to $12.0 \%$, and maximum directional slopes had a median of $0.59 \%$ and a range of -1.9 to $10.7 \%$ (note that this range skews positive because this measure aimed to capture uphill slopes from parcels to bikeways preferentially). For each of the specific bikeway types, the medians and ranges were typically higher because the distances to them were longer, providing more distance to achieve a higher maximum slope. Median slopes were consistently at least twice as high in Vancouver, though the range in slopes was only slightly narrower in Montreal than Vancouver. 


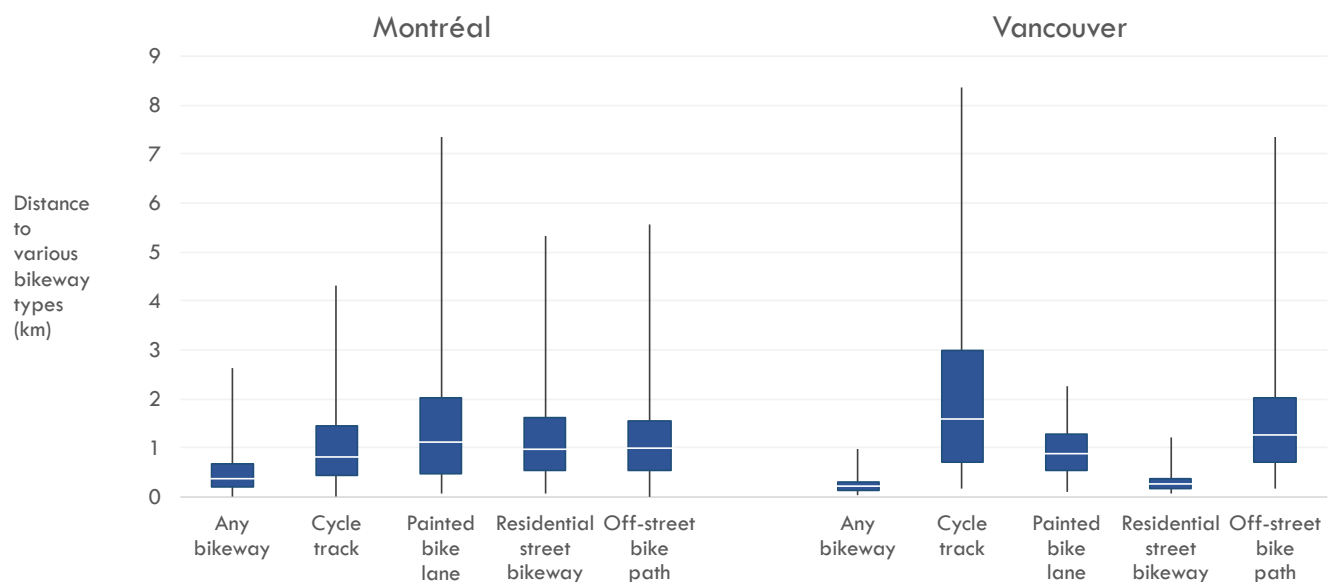

Figure 5: Box plots showing distributions of the mean distances from residential parcels to various bikeway types within 517 Montréal and 117 Vancouver census tracts. Bottom and top of box are 25th and 75th percentiles, white line is the median, whiskers show the range from minimum to maximum values

\subsection{Associations with cycling commute mode share}

Table 4 provides descriptive data for four categories of cycling commute mode share. Montréal had a higher proportion of census tracts with zero mode share, not surprising because its census consolidated subdivision includes not only urban but also suburban and rural areas. In addition to the large number of census tracts where no one commuted by bike, Montréal also included a large number with mode shares of $7 \%$ and higher $(n=87)$.

Table 4: Census tracts categorized by cycling commute mode share: descriptives for various characteristics

\begin{tabular}{|c|c|c|c|c|c|}
\hline & & \multicolumn{4}{|c|}{ Cycling commute mode share categories (\%) } \\
\hline & & 0 & 0.5 to $<2.5$ & 2.5 to $<7$ & 7 to 20.4 \\
\hline \multicolumn{2}{|c|}{ Number of census tracts } & 203 & 156 & 163 & 112 \\
\hline \multirow[t]{2}{*}{$\%$ of census tracts } & Montréal $(\mathrm{n}=517)$ & 35.6 & 24.0 & 23.6 & 16.8 \\
\hline & Vancouver $(\mathrm{n}=117)$ & 16.2 & 27.4 & 35.0 & 21.4 \\
\hline \multicolumn{2}{|c|}{$\%$ of bike commuters who were female } & - & 11.2 & 30.3 & 43.5 \\
\hline \multicolumn{6}{|c|}{ Mean distance $(\mathrm{km})$ to } \\
\hline \multicolumn{2}{|l|}{ Any bikeway } & 0.63 & 0.50 & 0.33 & 0.30 \\
\hline \multicolumn{2}{|l|}{ Cycle tracks } & 1.41 & 1.42 & 1.14 & 0.79 \\
\hline \multicolumn{2}{|c|}{ Painted bike lanes } & 1.68 & 1.39 & 1.06 & 0.84 \\
\hline \multicolumn{2}{|c|}{ Residential street bikeways } & 1.42 & 1.24 & 0.69 & 0.69 \\
\hline \multicolumn{2}{|c|}{ Off-street bike paths } & 1.35 & 1.27 & 1.20 & 0.94 \\
\hline \multicolumn{2}{|c|}{$\begin{array}{l}\text { Mean maximum uphill slope (\%) on } \\
\text { route to nearest bikeway }\end{array}$} & 0.94 & 0.94 & 0.63 & 0.68 \\
\hline \multicolumn{2}{|c|}{ Median commute time (minutes) } & 30.1 & 26.0 & 25.7 & 25.5 \\
\hline
\end{tabular}

- = Not applicable

In census tracts with higher cycling mode shares, the proportions of bike commuters who were female were considerably higher. Census tracts with higher mode shares had consistently closer mean proximities to any bikeway and to each of the four bikeway types. Census tracts with higher mode shares also had lower mean maximum directional slopes to the nearest bikeway of any type, but no pattern was seen for absolute slopes or for slopes associated with routes to the four bikeway types (data not shown). Commute times were somewhat shorter on average in census tracts with higher mode shares, though the 
data here obscure the non-linear relationship between cycling mode share and commute time (shown in Figure 3).

Table 5 shows the results of inferential analyses of the associations between cycling commute mode share and city, distance to bikeways, maximum directional slope to the nearest bikeway, and commute time (categorized as in Figure 3) for all commuters. In bivariate analyses, each of the independent variables showed a statistically significant association with mode share. The overall lower mode share in Montréal than Vancouver was evident in these analyses at the census tract level. Closer proximity to any bikeway was associated with more cycle commuting; one-kilometer closer proximity was associated with four times higher cycling commute mode share. One-kilometer closer proximity to cycle tracks was associated with more cycle commuting in both cities. Associations with all other individual bikeway types differed by city. In Montréal, all bikeway types were associated with higher cycling commute mode share. In Vancouver, residential street bikeways had strong associations with cycling commute mode share, but proximities to painted bike lanes and off-street bike paths were not associated with higher mode share. Higher maximum directional (uphill) slopes along the route to the nearest bikeway were associated with lower cycling mode share. Compared to census tracts with average commute times of 30 minutes or more, those with commute times of 20 to 29 minutes had higher cycling mode share.

In Models 1 and 2 that examined adjusted associations, city and slope were no longer significantly related to cycling mode share, but proximity to bikeways and commute time showed patterns similar to the bivariate analyses. In Model 2, proximity to cycle tracks had somewhat stronger associations than in bivariate analyses, whereas associations with the other bikeway types diminished in strength. Residential street bikeways remained important in Vancouver. The higher AICc for Model 2 indicates that including the four specific bikeway types did not add value over the simpler Model 1.

Table 6 shows the results of separate modelling for male and female commuters. Overall, the associations were similar to those for all commuters, but male commuters had somewhat weaker associations and females had stronger associations, particularly for any bikeway (Models 3 vs. 5), cycle tracks, and Vancouver residential street bikeways (Models 4 vs. 6). Stronger associations with commute times were also observed for female commuters. As for the models for all commuters combined, the AICc were lower for the simpler models in the sex-specific analyses. 
Table 5: Associations between cycling commute mode share and city, proximity to bikeways, directional slope to bikeways, and commute time (N, every analysis = 634 census tracts, 517 in Montréal and 117 in Vancouver)

\begin{tabular}{|c|c|c|c|c|c|c|c|}
\hline & & \multicolumn{2}{|c|}{$\begin{array}{l}\text { Bivariate analyses } \\
\text { All commuters }\end{array}$} & \multicolumn{2}{|c|}{$\begin{array}{l}\text { Model } 1 \\
\text { All commuters }\end{array}$} & \multicolumn{2}{|c|}{$\begin{array}{l}\text { Model } 2 \\
\text { All commuters }\end{array}$} \\
\hline & & $\mathrm{RR}$ & $\beta(\mathrm{SE})$ & $\mathrm{RR}$ & $\beta(\mathrm{SE})$ & $\mathrm{RR}$ & $\beta(\mathrm{SE})$ \\
\hline Montréal & & 0.63 & $-0.46(0.099)^{* * *}$ & 1.04 & $0.041(0.11)$ & 1.61 & $0.47(0.35)$ \\
\hline Vancouver & & 1 & (reference) & 1 & (reference) & 1 & (reference) \\
\hline \multicolumn{8}{|l|}{ Closer proximity $(1 \mathrm{~km})$ to } \\
\hline Any bikeway & Both cities & 4.44 & $1.49(0.18)^{* * *}$ & 3.91 & $1.36(0.20)^{* * *}$ & & \\
\hline Cycle track & Both cities & 1.23 & $0.21(0.052)^{* * *}$ & & - & 1.54 & $0.44(0.064)^{* * *}$ \\
\hline \multirow[t]{2}{*}{ Painted bike lane } & Montréal & 1.62 & $0.48(0.065)^{* * *}$ & & - & 1.53 & $0.43(0.056)^{* * *}$ \\
\hline & Vancouver & 0.87 & $-0.13(0.15)$ & & - & 0.54 & $-0.63(0.14)^{* * *}$ \\
\hline \multirow[t]{2}{*}{ Residential street bikeway } & Montréal & 1.68 & $0.52(0.081)^{* * *}$ & & - & 1.37 & $0.32(0.066)^{* * *}$ \\
\hline & Vancouver & 5.05 & $1.62(0.47)^{* * *}$ & & - & 3.17 & $1.15(0.41)^{* *}$ \\
\hline \multirow[t]{2}{*}{ Off street bike path } & Montréal & 1.58 & $0.46(0.088)^{* * *}$ & & - & 1.33 & $0.28(0.082)^{* * *}$ \\
\hline & Vancouver & 0.96 & $-0.037(0.067)$ & & - & 0.43 & $-0.83(0.11)^{* * *}$ \\
\hline $\begin{array}{l}\text { Greater uphill slope (1\%) } \\
\text { on route to nearest bikeway }\end{array}$ & & 0.88 & $-0.13(0.052)^{* *}$ & 0.99 & $-0.007(0.044)$ & 0.97 & $-0.027(0.036)$ \\
\hline \multicolumn{8}{|l|}{ Commute time } \\
\hline$<20$ minutes & & 0.98 & $-0.016(0.37)$ & 0.7 & $-0.35(0.35)$ & 0.77 & $-0.26(0.31)$ \\
\hline 20-24 minutes & & 1.94 & $0.66(0.11)^{* * *}$ & 1.57 & $0.46(0.12)^{* * *}$ & 1.53 & $0.43(0.10)^{* * *}$ \\
\hline 25-29 minutes & & 1.28 & $0.25(0.042)^{*}$ & 1.18 & $0.17(0.12)$ & 1.16 & $0.15(0.10)$ \\
\hline$\geq 30$ minutes & & 1 & (reference) & 1 & (reference) & 1 & (reference) \\
\hline Model AICc & & & - & & 623 & & 688 \\
\hline
\end{tabular}

$\mathrm{RR}=\mathrm{e}^{\beta}=$ relative rate (ratio of cycling commute mode shares) for each one-unit change or category change in the independent variable $\beta=$ coefficient

$\mathrm{SE}=$ standard error of the coefficient

* Statistically significant $\mathrm{p}<0.05 ;{ }^{* *} \mathrm{p}<0.01 ;{ }^{* * *} \mathrm{p}<0.001$

- = Not applicable

Bold indicates RR that are in the hypothesized direction and statistically significant 
Table 6: Sex-specific associations between cycling commute mode share and city, proximity to bikeways, directional slope to bikeways, and commute time $(\mathrm{N}$, every analysis = 634 census tracts, 517 in Montréal and 117 in Vancouver)

\begin{tabular}{|c|c|c|c|c|c|c|c|c|c|}
\hline & \multirow{2}{*}{\multicolumn{2}{|c|}{$\begin{array}{l}\text { Model } 3 \\
\text { Male commuters }\end{array}$}} & \multirow{2}{*}{\multicolumn{2}{|c|}{$\begin{array}{l}\text { Model } 4 \\
\text { Male commuters }\end{array}$}} & \multirow{2}{*}{\multicolumn{2}{|c|}{$\begin{array}{l}\text { Model } 5 \\
\text { Female commuters }\end{array}$}} & \multirow{2}{*}{\multicolumn{2}{|c|}{$\begin{array}{l}\text { Model } 6 \\
\text { Female commuters }\end{array}$}} \\
\hline & & & & & & & & & \\
\hline & & $\mathrm{RR}$ & $\beta(\mathrm{SE})$ & $\mathrm{RR}$ & $\beta(\mathrm{SE})$ & $\mathrm{RR}$ & $\beta(\mathrm{SE})$ & $\mathrm{RR}$ & $\beta(\mathrm{SE})$ \\
\hline Montréal & & 1.07 & $0.063(0.099)$ & 1.60 & $0.47(0.33)$ & 1.02 & $0.023(0.16)$ & 1.88 & $0.63(0.56)$ \\
\hline Vancouver & & 1 & (reference) & 1 & (reference) & 1 & (reference) & 1 & (reference) \\
\hline \multicolumn{10}{|l|}{ Closer proximity $(1 \mathrm{~km})$ to } \\
\hline Any bikeway & Both cities & 3.34 & $1.21(0.17)^{* * *}$ & & - & 5.71 & $1.74(0.33)^{* * *}$ & & - \\
\hline Cycle track & Both cities & & - & 1.41 & $0.34(0.058)^{* * *}$ & & - & 1.86 & $0.62(0.10)^{* * *}$ \\
\hline \multirow[t]{2}{*}{ Painted bike lane } & Montréal & & - & 1.43 & $0.36(0.050)^{* * *}$ & & - & 1.74 & $0.56(0.095)^{* * *}$ \\
\hline & Vancouver & & - & 0.57 & $-0.57(0.13)^{* * *}$ & & - & 0.44 & $-0.80(0.21)^{* * *}$ \\
\hline \multirow[t]{2}{*}{ Residential street bikeway } & Montréal & & - & 1.33 & $0.28(0.058)^{* * *}$ & & - & 1.51 & $0.41(0.11)^{* * *}$ \\
\hline & Vancouver & & - & 2.78 & $1.02(0.38)^{* *}$ & & - & 5.13 & $1.64(0.65)^{* *}$ \\
\hline \multirow[t]{2}{*}{ Off street bike path } & Montréal & & - & 1.26 & $0.23(0.073)^{* *}$ & & - & 1.54 & $0.43(0.13)^{* * *}$ \\
\hline & Vancouver & & - & 0.51 & $-0.68(0.10)^{* * *}$ & & - & 0.31 & $-1.18(0.17)^{* * *}$ \\
\hline \multicolumn{2}{|l|}{$\begin{array}{l}\text { Greater uphill slope (1\%) on } \\
\text { route to nearest bikeway }\end{array}$} & 0.98 & $-0.015(0.040)$ & 0.96 & $-0.043(0.035)$ & 1.02 & $0.017(0.065)$ & 1.00 & $0.0012(0.051)$ \\
\hline \multicolumn{10}{|l|}{ Commute time } \\
\hline \multicolumn{2}{|l|}{$<20$ minutes } & 1.17 & $0.16(0.24)$ & 1.14 & $0.13(0.22)$ & 0.52 & $-0.65(0.60)$ & 0.65 & $-0.43(0.54)$ \\
\hline \multicolumn{2}{|l|}{ 20-24 minutes } & 1.49 & $0.40(0.11)^{* * *}$ & 1.47 & $0.39(0.10)^{* * *}$ & 1.89 & $0.64(0.17)^{* * *}$ & 1.74 & $0.56(0.15)^{* * *}$ \\
\hline \multicolumn{2}{|l|}{ 25-29 minutes } & 1.21 & $0.19(0.10)$ & 1.13 & $0.12(0.09)$ & 1.73 & $0.55(0.18)^{* *}$ & 1.53 & $0.42(0.16)^{* *}$ \\
\hline \multicolumn{2}{|l|}{$\geq 30$ minutes } & 1 & (reference) & 1 & (reference) & 1 & (reference) & 1 & (reference) \\
\hline \multicolumn{2}{|l|}{ Model AICc } & & 706 & & 767 & & 520 & & 560 \\
\hline $\begin{array}{l}\mathrm{RR}=\mathrm{e}^{\beta}=\text { relative rate (ratio } \\
\beta=\text { coefficient } \\
\mathrm{SE}=\text { standard error of the co } \\
*^{* *} \text { Statistically significant } \mathrm{p}< \\
\text { - Not applicable }\end{array}$ & $\begin{array}{l}\text { f cycling com } \\
\text { fficient } \\
0.01 \text {; }^{* * *} \mathrm{p}<\end{array}$ & mute $n$ & ode shares) for ea & one-un & change or catego & chang & the independent & variab & \\
\hline
\end{tabular}

\section{Discussion}

At the time of this analysis, 2011, Montréal and Vancouver had the highest cycling commute mode shares of Canadian cities with more than 500,000 people, yet these fell far short of country-wide levels in Finland, Sweden, Germany, Denmark, and the Netherlands (9 to 25\%) (Buehler \& Pucher, 2012a; Statistics Canada, 2011e). There is promise in the census tract data: many neighborhoods had mode shares in the range of those in northern European countries, highlighting the potential for growth in cycling. There was also evidence that Montréal and Vancouver commuters are very willing to use active modes of transportation: walking commute mode shares were higher. It is notable that even in census tracts with the longest average commute times, walking was more than twice as common as cycling. Walking infrastructure (sidewalks), although not available everywhere throughout these cities, is considerably more widespread than cycling infrastructure. In Denmark and the Netherlands, where provision for both cycling and walking is extensive, commute shares are similar for the two active transport modes (Buehler \& Pucher, 2012a). 


\subsection{Bikeway proximity and types}

Our analysis found that in Montréal and Vancouver neighborhoods where homes were more proximate to bikeways, cycling mode shares were considerably higher. The association was strong and the same in the two cities. The results are consistent with a recent study of neighborhood commuter cycling in 24 North American cities, and with studies that have compared mode shares between cities (Winters et al., 2016; Buehler \& Pucher, 2012b; Dill \& Carr, 2003).

What about the effect of bikeway types? Their impact was complicated by the very different cycling networks in Montréal and Vancouver. Montréal is known for its long-standing and extensive provision of cycle tracks, more than any other North American city (Lusk et al., 2011). In 2011, it had similar lengths of all four types of bikeways $(-100 \mathrm{~km})$ that together provided networks in the central and western areas of the census subdivision, but not complete coverage of the island. Vancouver took advantage of the grid layout of its streets to create a city-wide network of residential street bikeways $(-150 \mathrm{~km})$, but other bikeway types were much less common $(\leq 40 \mathrm{~km})$. Both cities had more bikeways of most types in their downtown core.

Previous studies of stated and revealed preferences for various bikeway types in the two cities suggest similar preferences, in the following order from most to least preferred: off-street bike paths, cycle tracks, painted bike lanes (Larsen \& El-Geneidy, 2011; Winters \& Teschke, 2010). Vancouver survey data also included residential street bikeways; they were ranked the same as cycle tracks. In this study examining commuter cycling mode shares, associations with bikeway type did not exactly parallel the order of route preferences. Cycle tracks had the same association with cycling mode shares in both cities, about 1.5 times higher cycling commute mode share with $1 \mathrm{~km}$ closer proximity. Cycle tracks provide especially safe space for cycling alongside major streets (Lusk et al., 2011; Teschke et al., 2012; Harris et al., 2013). Since such routes often provide access to work destinations, their consistent association with commute mode share is reasonable. In Montreal, the remaining three bikeway types had similar or slightly lower associations with cycling mode share. In Vancouver, residential street bikeways had the strongest association with mode share. These differences suggest that the network formed by all bikeway types in Montreal and by residential street bikeways in Vancouver may be a more important driver of cycling mode share than bikeway design characteristics. This idea is supported by the fact that the more complex models with each of the four bikeway types did not add value compared to the simpler "any bikeway" models. Proximity to painted bike lanes and off-street paths were not associated with greater mode share in Vancouver. This shows some evidence of route design preference: where a network was available via residential street bikeways augmented by cycle tracks, painted bike lanes that are the least preferred assumed little importance to commuters. Off-street bike paths are the most preferred route type, but many were in parks or along waterways that primarily served recreational uses rather than travel from homes to workplaces. (Supplementary Figures A and B provide maps that illustrate the differences in coverage of the bikeway types in the two cities.)

\subsection{Hills}

Others have found that hilliness influences cycling choices (Heinen, Van Wee, \& Maat, 2010). Flatter topography is preferred and cyclists have been shown to choose flatter routes (Broach, Dill, \& Gliebe, 2012; Winters, Davidson, Kao, \& Teschke, 2011). In the 24-city analysis, hilliness was associated with lower neighborhood-level cycling mode share, though the association was weaker than for bike infrastructure (Winters et al., 2016). In this study, we examined two measures of slope along the route from home to the nearest bikeway: maximum absolute slope and maximum directional slope (i.e., uphill from home to the bikeway). Only uphill slope was associated (inversely) with cycling mode share. It may 
be that people's decisions to cycle are most influenced by hills they need to climb as they leave home. We also examined whether slopes to particular bikeway types made more difference than the slope to the nearest bikeway; they did not. This may be because the distances to specific bikeway types were on average longer than to the nearest bikeway, so the maximum slopes could be more distant from home. This could have two impacts: distant hills may not have as much psychological deterrent effect, and it could be easier to find a route that skirts a more distant hill. Overall in our study, slope on the route to the nearest bikeway from home was not a major deterrent. Higher uphill slopes to the nearest bikeway were associated with lower mode share in the bivariate analysis, but not in the adjusted models. Other measures of slope not considered here may be more important (e.g., slope along a full route; slope variability) (Broach, Dill, \& Gliebe, 2012; Winters et al., 2011).

\subsection{Commute time}

Trip distance has been shown to influence cycling (Heinen, Van Wee, \& Maat, 2010). Quantitative studies examining linear relationships have found less cycling with longer trip distances (Heinen, Van Wee, \& Maat 2010; Larsen \& El-Geneidy, 2011; Broach, Dill, \& Gliebe, 2012; Zahabi, Chang, Miranda-Moreno, \& Patterson, 2016). We found a non-linear association, with lower cycling mode shares both where commute times were short (less than 20 minutes, i.e., walkable) and where they were long (at least 30 minutes, i.e., more likely by transit or driving). Active transportation researchers often posit walking for shorter distances and cycling for middle distances (Woodcock, Givoni, \& Morgan, 2013). We found empirical evidence of this pattern, confirmed in both bivariate analyses and adjusted models.

\subsection{Female/male differences}

We investigated cycling mode share for male and female commuters separately. Though almost half the commuters in Montréal and Vancouver were female, only about one-third of cycling commuters were, echoing the common finding in low cycling countries that men are much more likely to use this transport mode (Buehler \& Pucher, 2012a). The proportion of bike commuters who were female was not stable across census tracts. Where mode shares were low ( 0.5 to $2.5 \%)$, the proportion female was only $11 \%$; but where mode shares were high (at least $7 \%$ ), the proportion female was $44 \%$-approaching parity with males. This dramatic difference in the proportions of women cycling underscores how important it is to appeal to women to achieve high cycling mode shares. There is consistent evidence that routes without bike-specific infrastructure and without separation from motor vehicle traffic are more likely to deter women than men (Aldred et al., 2016; Winters \& Teschke, 2010; Garrard, Rose, \& Lo, 2008). In the separate models for male and female commuters, we observed stronger associations for any bikeway and each bikeway type among women, though confidence limits around the coefficients always overlapped. Commute time also made a greater difference to women; they were more likely to cycle at intermediate commute times (20-29 minutes) and less likely to cycle with short commute times where walking was common or with long commute times where transit and driving were most common. Combined these results suggest that adding infrastructure proximate to homes may especially encourage women to cycle for intermediate commute distances.

\subsection{Strengths and limitations}

This study investigated neighborhood-level commuter cycling mode share in two major Canadian cities with diverse cycling infrastructure and high (for North America) cycling mode share. It used large-sample national survey data, with input from households with approximately 460,000 residents in Montréal 
and 140,000 in Vancouver. It examined the potential influence not only of bikeway provision, but of bikeway type. It also examined male and female commuters separately.

Our results suggest that bikeways may primarily influence cycling via the network they form, and that their design characteristics may only play a prominent role once a network is available. To understand the relative importance of design vs. network, many more cities with different infrastructure layouts would need to be studied. This would require obtaining and checking data about bikeways and their types across all cities. In this study of two cities, we manually confirmed comparable bikeway types using Google Streetview.

Our study analyzed data at the census tract level, not the individual or the city level. Mode share is by definition a population-level attribute, one that is important to both public health and transport policy makers. Our study complements surveys or GPS observations of individuals to help understand whether evidence of individual stated or revealed preferences is reflected at the population level. It also complements studies that compare cycling mode shares between cities, to see if bike route proximity affects within-city differences in cycling.

While this study benefitted from the large size of the survey sample, it was also limited by the questions asked and the data publicly released. The survey queried the usual mode of transport to work, not all modes used or the frequency of travelling by each mode. (Schoner, Cao, \& Levinson, 2015) The survey was conducted in May 2011 and the time of year may have affected the usual mode of travel reported. We used commute time as a surrogate for trip distance, since the latter was not available in the NHS public release dataset. Commute times were reported in aggregate for all travel modes together, diminishing the concordance between commute time and distance, given different travel speeds. It is likely that commute time represents non-differential misclassification of commute distance. If true, commute distance measured more accurately would be expected to have an even stronger association with cycling commute mode share.

This study used cross-sectional data from a single census year, so no claim can be made about a temporal direction of effect. Although it is reasonable to expect that greater availability of bikeways leads to increased mode share, it is possible that cities install more infrastructure where cycling is higher. Evidence for the former is provided by two studies. A recent Montréal study used local survey data from 1998, 2003, and 2008 and found that cycling increased over time in response to greater accessibility of bike infrastructure (Zahabi et al., 2016). A Minneapolis-St. Paul study using census commute data from 1990 and 2000 found increases in cycling in zones near new bicycling facilities (Krizek, Barnes, \& Thompson, 2009). Cross-sectional data also cannot discern mechanisms that increase cycling, i.e., whether new bikeways increase cycling among existing area residents or attract new residents interested in cycling (self-selection) (Schoner et al., 2015). Evidence from a number of studies suggest that both mechanisms contribute (Schoner et al., 2015; Cao, Mokhtarian, \& Handy, 2009). Both are also likely to be welcomed by city planners and transport engineers trying to achieve higher cycling mode shares.

A valuable follow-up to our study would examine whether changes to both total bike infrastructure or specific bikeway types are associated with changes in neighborhood cycling mode shares, for example in the 2016 census. From 2011 to 2016, the total length of bikeways has increased 50\% in Montréal and $10 \%$ in Vancouver, with increases distributed differently by bikeway type, so there is a promising basis for comparison. It is interesting to consider the potential upside of increasing specific bikeway types based on our results. A one-kilometer greater proximity to cycle tracks was associated with 1.5 times higher cycling mode share. Given that high proportions of census tracts in both cities were more than $1 \mathrm{~km}$ from cycle tracks, increasing access to them would appear to be a promising investment. In Vancouver, residential street bikeways had an even stronger association with cycling mode share; onekilometer greater proximity was associated with three times higher cycling mode share. However almost 
all Vancouver census tracts were already at least this close, so increasing residential street bikeways might have an impact in only a few neighborhoods. Developing the density of the bikeway network may be the best choice of all, given that the strongest associations were observed for proximity to any bikeway type.

While our study specifically focused on proximity from home to bikeways, slopes on routes to bikeways, and commute times, it is important to note that many other factors may influence cycling commute mode share. Others have examined or hypothesized the influence of demographics (e.g., income, education, age, children at home, housing costs, vehicles in household, health), destinations and routes to them (e.g., bikeways, hills, turning movements, network connectivity and density, traffic volumes and speeds), and many other potential incentives or deterrents (parking availability and cost, transit availability, payments for cycling, end of trip facilities, weather and climate, experience of bike crashes, attitudes of family, friends and co-workers to cycling) (Broach, Dill, \& Gliebe, 2012; Heinen, et al., 2010; Larsen \& El-Geneidy, 2011; Schoner et al., 2015; Schoner \& Levinson, 2014; Wardman et al, 2007; Zahabi et al., 2016).

\section{$5 \quad$ Conclusions}

In Montréal and Vancouver, major Canadian cities with 2011 cycling commute mode shares of 2.7 and $4.3 \%$, respectively, there was substantial variation in cycling at the neighborhood level: 0 to $20.4 \%$. The variation in cycle commuting was associated with the proximity to any bikeway and with specific bikeway types. In both cities, proximity to cycle tracks was associated with higher cycling mode shares. Other bikeway types did not have similar associations in the two cities, and the pattern of results suggested that the network formed by other bikeway types may have been more important than the specific bikeway characteristics. Commute times also made a difference: neighborhoods with intermediate commute times (20 to 29 minutes on average) had the highest cycling commute mode shares. Uphill slopes on the routes to the nearest bikeway were associated with somewhat lower mode shares, but this effect was not observed in adjusted models. In neighborhoods where cycle commuting was more common, the proportion who were female approached parity with males. Both bikeway type and commute times had stronger associations with cycling mode share in women than men.

This study suggests that cycle tracks and a connected network of preferred routes are features that should be emphasized by transportation planners and engineers to achieve more cycling in urban areas. These features rank highly in female preferences, and this study found that more cycling by women was strongly related to higher overall cycling mode shares.

\section{Acknowledgements}

We appreciate the comments of the anonymous reviewers; they helped refine our approach, interpretation, and presentation. We thank Dr. Hui Shen for her recommendations on the analytical method and presentation of results. 


\section{References}

Aldred, R., Elliott, B., Woodcock, J., \& Goodman, A. (2016). Cycling provision separated from motor traffic: A systematic review exploring whether stated preferences vary by gender and age. Transport Reviews, 37(1) 29-55. http://www.tandfonline.com/doi/abs/10.1080/01441647.2016.1200156

Broach, J., Dill, J., \& Gliebe, J. (2012). Where do cyclists ride? A route choice model developed with revealed preference GPS data. Transportation Research Part A: Policy and Practice, 46(10), 1730-1740. http://www.sciencedirect.com/science/article/pii/S0965856412001164

Buehler, R., \& Dill, J. (2016). Bikeway networks: A review of effects on cycling. Transport Reviews, 36(1), 9-27. http://www.tandfonline.com/doi/abs/10.1080/01441647.2015.1069908

Buehler, R., \& Pucher, J. (2012a). Walking and cycling in Western Europe and the United States: Trends, policies, and lessons. TR News, 280, 34-42. http://onlinepubs.trb.org/onlinepubs/trnews/ trnews280WesternEurope.pdf

Buehler, R., \& Pucher, J. (2012b). Cycling to work in 90 large American cities: New evidence on the role of bike paths and lanes. Transportation, 39(2), 409-432. http://link.springer.com/article/10.1007/ s11116-011-9355-8

Cao, X., Mokhtarian, P. L., \& Handy, S. L. (2009). Examining the impacts of residential self-selection on travel behavior: A focus on empirical findings. Transport Reviews, 29(3), 359-395. http://www. tandfonline.com/doi/abs/10.1080/01441640802539195

Dill, J., \& Carr, T. (2003). Bicycle commuting and facilities in major US cities: If you build them, commuters will use them. Transportation Research Record, 1828, 116-123. http://trrjournalonline.trb. org/doi/pdf/10.3141/1828-14

Dill, J., \& Gliebe, J. (2008). Understanding and measuring bicycling behavior: A focus on travel time and route choice, OTREC-RR-08-03. Portland, OR: University of Portland, Oregon Transportation Research and Education Consortium. https://works.bepress.com/jennifer_dill/26/

Environment Canada. 2016. Canadian Climate Normals, 1981-2010 Climate Normals \& Averages. Retrieved from http://climate.weather.gc.ca/climate_normals/index_e.html

Garrard, J., Rose, G., \& Lo, S. K. (2008). Promoting transportation cycling for women: The role of bicycle infrastructure. Preventive medicine, 46(1), 55-59. http://www.sciencedirect.com/science/article/pii/S0091743507003039

Harris, M. A., Reynolds, C. C., Winters, M., Cripton, P. A., Shen, H., Chipman, M. L., Cusimano, M. D., Babul, S., Brubacher, J. R., Friedman, S. M., \& Hunte, G. (2013). Comparing the effects of infrastructure on bicycling injury at intersections and non-intersections using a case-crossover design. Injury Prevention, 19(5), 303-310. http://injuryprevention.bmj.com/content/early/2013/02/13/ injuryprev-2012-040561.full.pdf

Heinen, E., Van Wee, B., \& Maat, K. (2010). Commuting by bicycle: An overview of the literature. Transport reviews, 30(1), 59-96. http://www.tandfonline.com/doi/abs/10.1080/01441640903187001

Krizek, K. J., Barnes, G., \& Thompson, K. (2009). Analyzing the effect of bicycle facilities on commute mode share over time. Journal of Urban Planning and Development, 135(2), 66-73. http://kevinjkrizek.org/wp-content/uploads/2012/04/Analyzing_effect.pdf

Larsen, J., \& El-Geneidy, A. (2011). A travel behavior analysis of urban cycling facilities in Montréal, Canada. Transportation Research Part D: Transport and Environment, 16(2), 172-177. http://www. sciencedirect.com/science/article/pii/S1361920910001100

Lusk, A. C., Furth, P. G., Morency, P., Miranda-Moreno, L. F., Willett, W. C., \& Dennerlein, J. T. (2011). Risk of injury for bicycling on cycle tracks versus in the street. Injury prevention, 17(2), 131-135. http://injuryprevention.bmj.com/content/17/2/131.full.pdf 
Mueller, N., Rojas-Rueda, D., Cole-Hunter, T., de Nazelle, A., Dons, E., Gerike, R., Goetschi, T., Panis, L. I., Kahlmeier, S., \& Nieuwenhuijsen, M. (2015). Health impact assessment of active transportation: A systematic review. Preventive Medicine, 76, 103-114. http://www.sciencedirect.com/science/ article/pii/S0091743515001164

Oja, P., Titze, S., Bauman, A., De Geus, B., Krenn, P., Reger-Nash, B., \& Kohlberger, T. (2011). Health benefits of cycling: A systematic review. Scandinavian Journal of Medicine and Science in Sports, 21(4), 496-509. http://onlinelibrary.wiley.com/doi/10.1111/j.1600-0838.2011.01299.x/full

Reynolds, C. C., Harris, M. A., Teschke, K., Cripton, P. A., \& Winters, M. (2009). The impact of transportation infrastructure on bicycling injuries and crashes: A review of the literature. Environmental Health, 8(47). .http://ehjournal.biomedcentral.com/articles/10.1186/1476-069X-8-47

Schoner, J. E., Cao, J., \& Levinson, D. M. (2015). Catalysts and magnets: Built environment and bicycle commuting. Journal of Transport Geography, 47, 100-108. http://www.sciencedirect.com/ science/article/pii/S0966692315001301

Schoner, J. E., \& Levinson, D. M. (2014). The missing link: Bicycle infrastructure networks and ridership in 74 US cities. Transportation, 41(6), 1187-1204.

Statistics Canada (2011a). Census Dictionary. Catalogue no. 98-301-X2011001. Retrieved from https:// www12.statcan.gc.ca/census-recensement/2011/ref/dict/98-301-X2011001-eng.pdf

Statistics Canada. (2011b). National Household Survey. Record number 5178. Retrieved from http:// www23.statcan.gc.ca/imdb/p2SV.pl?Function=getSurvey\&SDDS=5178

Statistics Canada. (2011c). National Household Survey: Final response rates, census subdivisions. Retrieved from https://www12.statcan.gc.ca/nhs-enm/2011/ref/about-apropos/nhs-enm_r013.cfm?Lang=E

Statistics Canada. (2011d). Table 282-0129 Labor force survey estimates (LFS), by census metropolitan area based on 2011 Census boundaries, sex and age group. Retrieved from http://www5.statcan. gc.ca/cansim/a26?lang=eng\&id=2820129

Statistics Canada. (2011e). National Household Survey Focus on Geography Series. Census subdivisions, with 5,000-plus population, grouped by provinces and territories. Retrieved from http://www12. statcan.gc.ca/nhs-enm/2011/as-sa/fogs-spg/Pages/CSDSelector.cfm?lang=E\&level=4\#PR59

Teschke, K., Harris, M. A., Reynolds, C. C., Winters, M., Babul, S., Chipman, M., Cusimano, M. D., Brubacher, J. R., Hunte, G., Friedman, S. M., \& Monro, M. (2012). Route infrastructure and the risk of injuries to bicyclists: A case-crossover study. American Journal of Public Health, 102(12), 2336-2343. http://ajph.aphapublications.org/doi/pdf/10.2105/AJPH.2012.300762

Wardman, M., Tight, M., \& Page, M. (2007). Factors influencing the propensity to cycle to work. Transportation Research Part A: Policy and Practice, 41(4), 339-350. http://www.sciencedirect.com/ science/article/pii/S0965856406001212

Winters, M., \& Teschke, K. (2010). Route preferences among adults in the near market for bicycling: Findings of the Cycling in Cities study. American Journal of Health Promotion, 25(1), 40-47. http:// ahp.sagepub.com/content/25/1/40.abstract

Winters, M., Davidson, G., Kao, D., \& Teschke, K. (2011). Motivators and deterrents of bicycling: Comparing influences on decisions to ride. Transportation, 38(1), 153-168. http://link.springer. com/article/10.1007/s11116-010-9284-y

Winters, M., Teschke, K., Brauer, M., \& Fuller, D. (2016). Bike Score ${ }^{\bullet}$ Associations between urban bikeability and cycling behavior in 24 cities. International Journal of Behavioral Nutrition and Physical Activity, 13(18). https://ijbnpa.biomedcentral.com/articles/10.1186/s12966-016-0339-0

Winters, M., Teschke, K., Grant, M., Setton, E., \& Brauer, M. (2010). How far out of the way will we travel? Built environment influences on route selection for bicycle and car travel. Transportation Research Record, 2190, 1-10. http://trrjournalonline.trb.org/doi/pdf/10.3141/2190-01 
Woodcock, J., Givoni, M., \& Morgan, A. S. (2013). Health impact modelling of active travel visions for England and Wales using an Integrated Transport and Health Impact Modelling Tool (ITHIM). PLoS One, 8(1), e51462. http://journals.plos.org/plosone/article?id=10.1371/journal. pone.0051462

Zahabi, S. A. H., Chang, A., Miranda-Moreno, L. F., \& Patterson, Z. (2016). Exploring the link between the neighborhood typologies, bicycle infrastructure and commuting cycling over time and the potential impact on commuter GHG emissions. Transportation Research Part D: Transport and Environment, 47, 89-103. http://www.sciencedirect.com/science/article/pii/S136192091630270X
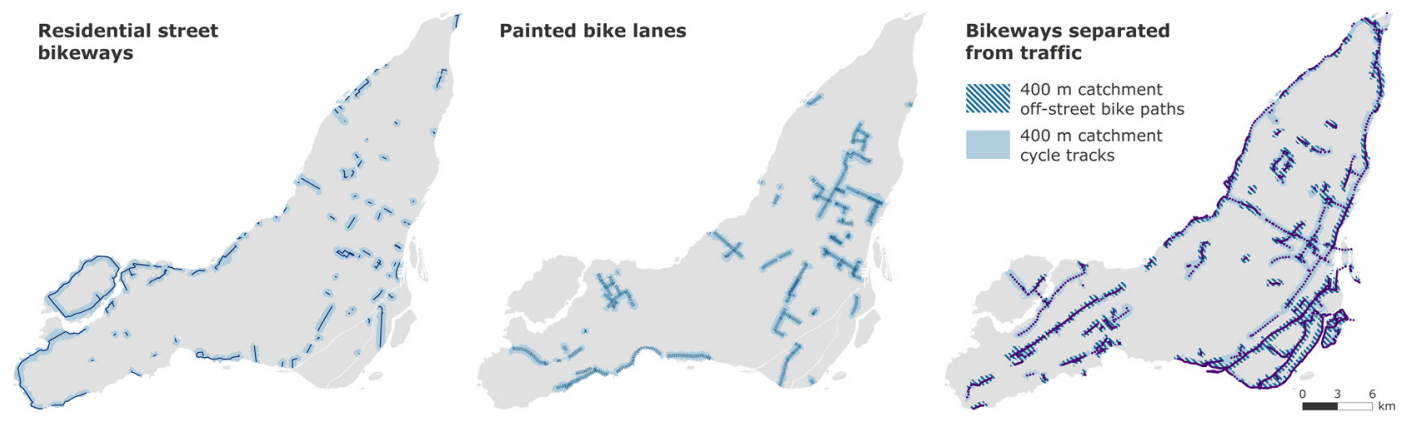

Supplemental Figure A: Map of Montréal showing distributions of various bikeway types
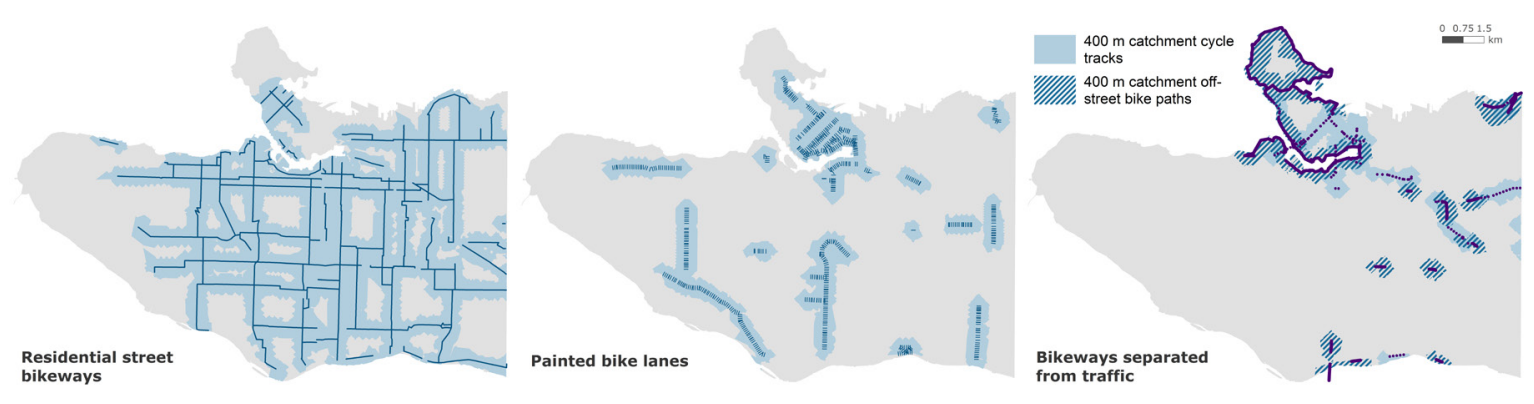

Supplemental Figure B: Map of Vancouver showing distributions of various bikeway types 